\title{
Associations between Healthcare Resources and Healthy Life Expectancy: A Descriptive Study across Secondary Medical Areas in Japan
}

\author{
Rikuya Hosokawa ${ }^{1, *(\mathbb{D}}$, Toshiyuki Ojima ${ }^{2}$, Tomoya Myojin ${ }^{3}$, Jun Aida ${ }^{4,5}$, Katsunori Kondo 6,7,8 \\ and Naoki Kondo ${ }^{9,10}$ \\ 1 Department of Human Health Sciences, Graduate School of Medicine, Kyoto University, \\ Kyoto 606-8507, Japan \\ 2 Department of Community Health and Preventive Medicine, Hamamatsu University School of Medicine, \\ Shizuoka 431-3192, Japan; ojima@hama-med.ac.jp \\ 3 Department of Public Health, Health Management and Policy, Nara Medical University, Nara 634-8521, \\ Japan; motoya1014@gmail.com \\ 4 Department of Oral Health Promotion, Graduate School of Medical and Dental Sciences, Tokyo Medical and \\ Dental University, Tokyo 113-8549, Japan; junaida916@gmail.com \\ 5 Division for Regional Community Development, Liaison Center for Innovative Dentistry, Graduate School \\ of Dentistry, Tohoku University, Miyagi 980-8575, Japan \\ 6 Center for Preventive Medical Sciences, Chiba University, Chiba 263-8522, Japan; kkondo@kkondo.net \\ 7 Center for Well-being and Society, Nihon Fukushi University, Aichi 470-3295, Japan \\ 8 Center for Gerontology and Social Science, National Center for Geriatrics and Gerontology, \\ Aichi 474-8511, Japan \\ 9 Department of Health and Social Behavior, School of Public Health, The University of Tokyo, Tokyo \\ 113-0033, Japan; nkondo@m.u-tokyo.ac.jp \\ 10 Department of Health Education and Health Sociology, School of Public Health, The University of Tokyo, \\ Tokyo 113-0033, Japan \\ * Correspondence: hosokawa.rikuya.4r@kyoto-u.ac.jp; Tel.: +81-75-751-4154
}

Received: 31 July 2020; Accepted: 26 August 2020; Published: 29 August 2020

\begin{abstract}
Japan has the highest life expectancy in the world. However, this does not guarantee an improved quality of life. There is a gap between life expectancy and healthy life expectancy. This study aimed to reveal the features of healthy life expectancy across all secondary medical areas $(n=344)$ in Japan and examine the relationship among healthcare resources, life expectancy, and healthy life expectancy at birth. Data were collected from Japan's population registry and long-term insurance records. Differences in healthy life expectancy by gender were calculated using the Sullivan method. Maps of healthy life expectancy were drawn up. Descriptive statistics and correlation analysis were used for analysis. The findings revealed significant regional disparities. The number of doctors and therapists, support clinics for home healthcare facilities and home-visit treatments, and dentistry expenditure per capita were positively correlated with life expectancy and healthy life expectancy (correlation coefficients $>0.2$ ). They also revealed gender differences. Despite controlling for population density, inequalities in healthy life expectancy were observed, highlighting the need to promote social policies to reduce regional disparities. Japanese policymakers should consider optimal levels of health resources to improve life expectancy and healthy life expectancy. The geographical distribution of healthcare resources should also be reconstituted.
\end{abstract}

Keywords: life expectancy; healthy life expectancy; Sullivan method; healthcare resources; secondary medical area; Japan 


\section{Introduction}

Although life expectancy (LE) is an indicator of health status, there is a growing interest in the quality of life (QOL) of older adults during their later years. Healthy life expectancy (HLE) is a useful indicator of a population's overall health, reflecting length of life as well as QOL [1-3]. HLE refers to an individual's length of life lived without limitations in daily activities. In addition, HLE at birth is an important indicator of a population's health status and QOL [4]. Moreover, HLE combines data on both mortality and morbidity [5]. It summarizes mortality and non-fatal outcomes in a single measure of the general population's health.

The increasing age of the global population warrants greater attention to disorders. Although both LE and HLE have improved, LE with disability has also increased. In an aging society, as greater age puts increased pressure on social systems, extending HLE and shortening LE with disability are becoming global priorities [6]. Moreover, LE and HLE differ; longer LE increases the risk for disability [7,8]. Meanwhile, HLE increases more slowly than LE [9]. Efforts to shorten this gap and encourage healthy aging are needed. Moreover, HLE has been used to compare the health status of various populations and explore health inequalities within a given population. Inequalities in LE and HLE can be observed across multiple regions and countries. However, little is known regarding the determinants of inequalities in HLE at the regional level.

According to the World Health Organization (WHO), Japan had the highest average estimated LE at birth in 2016 with 84.2 years [10]. The LE of females in Japan was ranked first in the world with 87.2 years, while the LE of men was ranked sixth with 81.1 years. Similarly, Japan had the highest average HLE in 2016 with 74.8 years. However, the factors attributed to Japan's longevity have been a source of debate. It is difficult to identify a specific factor since there are possibilities of interplay among various factors, such as healthcare system and lifestyle. According to studies, some of the possible factors include the country's high living standards, medical advances, and the universal and accessible healthcare system [11,12].

Japan has achieved satisfactory population health at a reasonably low cost; in fact, the Japanese have universal health coverage with their National Health Insurance system. Although Japan has the highest levels of LE and HLE among the members of the Organisation for Economic Co-operation and Development (OECD), its healthcare expenditure as a share of Gross Domestic Product is below that of most OECD countries [13]. In addition, regarding lifestyle, the Japanese diet has a relatively lower calorie and fat intake compared to that of developed economies, such as Europe and North America. Several studies suggest that adopting a Japanese diet tends to reduce the risk of cardiovascular disease and metabolic syndrome [14,15].

However, on average, the Japanese spend the last 9.4 years (11.2\% of LE) of their lives with poor health, mobility impairments, or in a bedridden state. The duration of the difference between LE and HLE represents the average number of years with poor health (i.e., unhealthy life expectancy) [16]. In Japan, there is still a gap between LE and HLE [17]. Although the Japanese have the highest LE and HLE in the world, unhealthy life expectancy is not necessarily at the highest levels (e.g., Singapore: 6.8 years; $8.2 \%$ of LE, Spain: 9.3 years; $11.2 \%$ of LE, Switzerland: 9.8 years; $11.8 \%$ of LE) [10]. In addition, having high LE does not necessarily mean high QOL. Thus, in recent years, the Japanese government has focused on extending HLE.

Extension of HLE was one of the main goals presented in "The Second Term of the National Health Promotion Movement in the Twenty First Century" (Health Japan 21, the Second Term) $[18,19]$. This 10-year nationwide health promotion project from 2013 to fiscal year 2022 was developed by the Ministry of Health, Labour, and Welfare with two main goals: extending HLE and reducing health inequality. Health inequality refers to the gap in HLE among prefectures (Japan is divided into 47 administrative districts known as prefectures). A 2016 study calculated the HLE for each prefecture using data from the Comprehensive Survey of Living Conditions and reported a difference of 2.70 years for females and 2.00 years for males [20]. Although Japan has been successful in their health outcome statuses (e.g., reducing mortality and disability), variations in health outcome statuses 
between prefectures are increasing [21]. In fact, the government is considering setting a target health expenditure level for each prefecture to address the issue of rapid increase and regional variations in health expenditure. Although small municipal area analyses were conducted, the standard errors were too large. Furthermore, the population of several municipal areas is too small to provide medical care. Thus, to implement effective health policies, further descriptive analyses in smaller areas are required. It is important to clarify the difference in HLE in each healthcare accessible area and implement effective policies.

In Japan, healthcare service areas have been established to provide efficient medical services. Under the Medical Care Law, these areas are required to provide general healthcare supplies through their prefectural governments [22,23]. Primary medical service areas consist of approximately 1700 districts; secondary medical areas consist of 344 jurisdictions; and tertiary medical service areas consist of 52 areas. The secondary medical area is a region where general inpatient medical care can be provided. In addition, the medical provision system is planned based on area unit to maintain medical resources (e.g., number of beds and number of clinic facilities). The characteristics of each region with respect to HLE by prefecture levels have been reported in multiple studies. However, these studies have focused on health promotion and care prevention measures. There is a lack of assessment in units of administrative districts that are directly linked to administrative activities.

The Japanese population has been rapidly aging because of decreasing birth rates and increasing LE. In fact, Japan has the highest proportion of older adults in the world [24]. In 1999, the population of those aged 65 years and older was $16.7 \%$ [25]. In 2019, older adults comprised $28.4 \%$ of the total population [26]. This figure is expected to increase to $35.3 \%$ by $2040,37.7 \%$ by 2050 , and $38.1 \%$ by 2060 [27]. Rapid aging has a substantial effect on disease structure, which is leading Japan to an advanced stage of epidemiological transitions [12,28]. Older adults experience a higher number of chronic diseases and multiple morbidities that require long-term care and increase healthcare expenditure. However, the characteristics of population aging and epidemiological transition differ by region, which can have a significant impact on healthcare system performance [29]. These factors influence the social determinants of health and may increase imbalances within the healthcare system [30]. Thus, it is important to develop a healthcare system that matches the actual conditions of each region. However, the actual distribution of the difference in HLE among secondary medical areas has yet to be clarified. Therefore, understanding the regional characteristics of the medical service system related to HLE in secondary medical areas is important to have a more effective approach in extending HLE and healthy aging policies.

In Japan, one of the most important policy challenges is the creation of an economically active aging society and a strong healthcare system to sustain it. Although the medical provision system in secondary medical areas is designed to be modified as necessary, it cannot always address regional disparities in healthcare resource distribution [31]. Japan is ranked 18th among OECD member states for low-cost medical care, and ranked first for its high level of health attainment and HLE [32,33]. Japan has one of the best healthcare systems in the world in terms of availability and cost. Many researchers attribute the success of its healthcare system to the dexterous balance of supply and demand and control over medical costs through the universal health insurance system [12,13]. However, Japan's super-aging population is putting more pressure on its health system's sustainability. Although the characteristics of the Japanese healthcare system have the advantages of healthcare availability, such healthcare systems cannot meet the needs of a super-aging society. Prior studies suggest that LE is influenced by healthcare resources, such as hospital bed capacity, healthcare workforce, and healthcare expenditure [34,35]. Healthcare resources have short- and long-term effects on health, which have been studied in terms of health output (e.g., number of medical doctors) or health outcomes (e.g., LE and mortality rate). However, the effects of healthcare resources on the average LE and HLE have not been fully elucidated.

Ultimately, good overall population health is key to a productive and developed society. Healthcare resources, including number of beds and workforce size, is one of the most important factors that 
influence health status [36]. Although Japan's healthcare system is the most organized in the world, there are functional differences between regions that need to be addressed [37]. There is a gap in terms of equal distribution of beds, staff, and doctors among all prefectures. Thus, it is necessary to clarify the relationship between medical care resources (i.e., hospital beds, healthcare workforce, home healthcare service, and healthcare expenditure) and HLE to contribute to developing effective policies to extend HLE.

\section{Current Study}

This study aimed to identify the descriptive features of the distribution of HLE across secondary medical areas in Japan. In addition, it sought to clarify the relationship between healthcare resources, LE, and HLE through a geographical study of all secondary medical areas in Japan. The findings may have many implications for other countries with super-aging societies. However, research into the descriptive features of HLE and the associations between LE, HLE, and healthcare resources in the context of Japan is limited. This study comes at a time when health policymakers are reviewing and assessing priorities for action in Japan. It supports mapping of HLE in Japan, and the findings may contribute to the development of national and region-specific health policies for healthcare resources.

\section{Materials and Methods}

\subsection{Measures}

\subsubsection{Outcome Variables: Life Expectancy and Healthy Life Expectancy}

We estimated HLE across all 344 secondary medical areas in Japan using the Sullivan method, which is based on age-specific death rates and years lived with disability [38]. In this method, by applying age-specific prevalence rates of a particular unhealthy state to a life table function (i.e., number of person-years lived in each age interval), the total LE is divided into person-years lived with good health (i.e., HLE). HLE is a measure of population health that estimates the expected number of "healthy years" (i.e., years spent in good health) of individuals at a given age. In addition, LE at birth was calculated using the population age standard.

To calculate LE and HLE, population data as of 2017 were obtained from the resident registry of Japan [39]. Mortality data were obtained from the Vital Statistics of Total Deaths in 2016-2018 [40]. Data on care needs were obtained from the Report on Long-Term Care Insurance Services. In this study, "healthy" was defined as the period of time spent without limitation in daily activities, while "unhealthy" was the period of time spent with limitations in daily activities. The Japanese care system is divided into care levels from 1 through 5, based on individuals' care needs as certified by Japan's long-term care insurance system (see Table S1) [41,42]. Data on unhealthy people, which included those at care level 2 (almost bedridden) and higher, were obtained from the 2017 long-term care insurance data [43]. The present study classified those at level 2 or greater as "having care needs" (i.e., unhealthy); all other levels were classified as "almost no care needs" (i.e., healthy).

\subsubsection{Explanatory Variable: Healthcare Resources}

In this study, we used healthcare resources (i.e., hospital beds, healthcare workforce, home healthcare service, and healthcare expenditure) as the explanatory variable. The population ratio of healthcare resources across all 344 secondary medical areas was calculated [44-46]. We used data from the Survey of Medical Institutions, Annual Report on Health, Labour and Welfare, and National Database of Health Insurance Claims and Specific Health Checkups of Japan [44-46]. Hospital beds (i.e., number of beds) included curative (acute), rehabilitative, and long-term care beds per 1000 residents. The healthcare workforce (i.e., number of health professionals) consisted of doctors, nurses, and therapists per 1000 residents. Therapists included physical, occupational, and speech-hearing therapists. Home healthcare services (i.e., number of facilities) included support hospitals and clinics 
for home healthcare per 1000 residents, and home-visit care facilities per 1000 residents. The standard for healthcare facilities established by the Ministry of Health, Labour and Welfare requires hospitals and clinics to supplement home healthcare; medical facilities support patients living at home by providing medical care 24 hours a day [47]. A facility with at least 20 beds is considered a "support hospital of home health care", while a facility with fewer than 20 beds is a "support clinic of home health care".

\subsubsection{Confounding Variable: Population Density}

Studies show that population density is significantly related to healthcare resources $[37,48,49]$. Considering that the location of healthcare resources is largely determined by the population of the area, we investigated the associations between healthcare resources, LE, and HLE at birth by performing partial correlation analyses after controlling for population density using data obtained from the Population Census of Japan [50]. Since the population density has a logarithmic normal distribution, the logarithm of the population density was calculated.

\subsection{Statistical Analyses}

IBM SPSS Statistics Version 26 (IBM Corp, Armonk, NY, USA) was used for data analyses. To examine the descriptive features of the distribution of HLE across secondary medical areas in Japan, it was divided into five categories by 20th percentiles and gender. Moreover, maps of HLE levels across Japan were drawn [51]. A chi-squared test was performed to assess the differences in HLE among eight regions (i.e., Hokkaido, Tohoku, Kanto, Chubu, Kinki, Chugoku, Shikoku, and Kyushu-Okinawa regions) by gender.

Associations between healthcare resources, LE, and HLE at birth were assessed using partial correlation analyses controlling for population density. In the analysis, correlations were significant at the $p<0.001$ level (two-tailed), and correlation coefficients greater than 0.2 were considered to indicate a positive correlation.

\section{Results}

\subsection{Descriptive Statistics for Life Expectancy and Healthy Life Expectancy at Birth}

Table 1 shows the descriptive statistics for LE and HLE at birth in years. The mean HLE at birth was 79.21 years (standard deviations 0.85 ) for males and 83.75 years (standard deviations 0.62 ) for females. Furthermore, a comparison of HLE in secondary medical areas revealed differences of 4.46 years (minimum 76.90, maximum 81.36) for males and 3.46 years (minimum 81.99, maximum 85.45) for females.

The nationwide distributions of HLE are presented in Figure 1 for males and Figure 2 for females. In the current study, chi-squared tests were performed to analyze the differences in HLE among eight regions (i.e., Hokkaido, Tohoku, Kanto, Chubu, Kinki, Chugoku, Shikoku, and Kyushu-Okinawa regions) by gender. For males, there were significant differences in HLE among the regions $(p<0.001)$. The proportion of secondary medical areas with short HLE tended to be higher in the northern part of Japan (Hokkaido and Tohoku regions), while the proportion of areas with high HLE was higher in the central (Chubu region) and west-central (Kinki regions) parts. Similarly, for females, there were significant differences in HLE among the regions $(p<0.001)$. The proportion of secondary medical areas with short HLE was higher in the northern (Tohoku region) and northern-central (Kanto region) parts of Japan, while the proportion of areas with high HLE was higher in the central (Chubu region) and southern (Kyushu-Okinawa regions) parts. These results indicated significant regional disparities; the common point is that for both males and females, the proportion of areas with short HLE was high in the northern part of Japan (Tohoku region), while the proportion of areas with high HLE was high in the central part (Chubu region). 


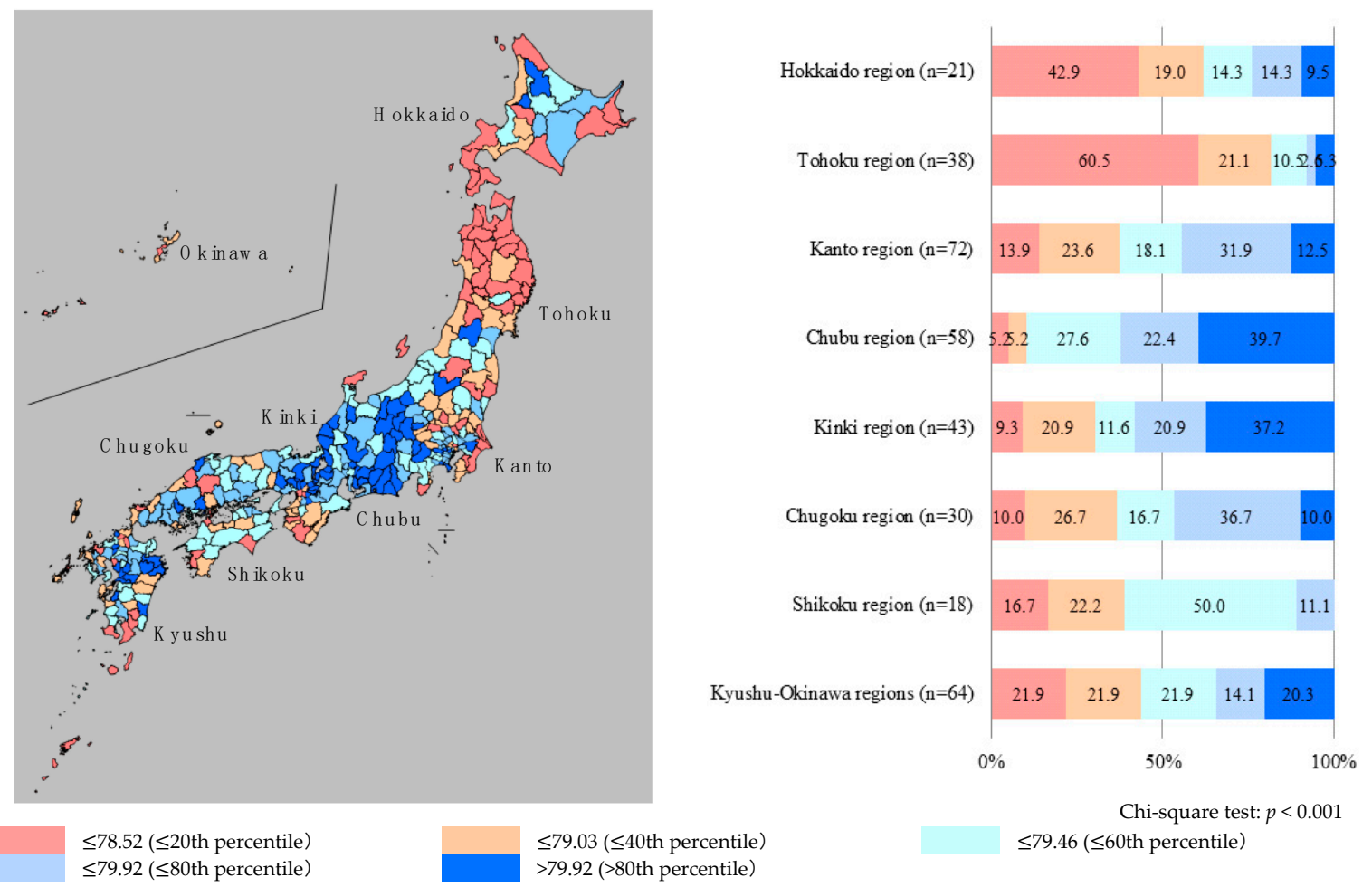

Figure 1. Distribution of healthy life expectancy for males in each secondary medical area. Note: Healthy life expectancy was divided into five categories, by 20th percentiles. The " $n$ " means the number of secondary medical areas in eight regions (Hokkaido, Tohoku, Kanto, Chubu, Kinki, Chugoku, Shikoku, and Kyushu-Okinawa regions).

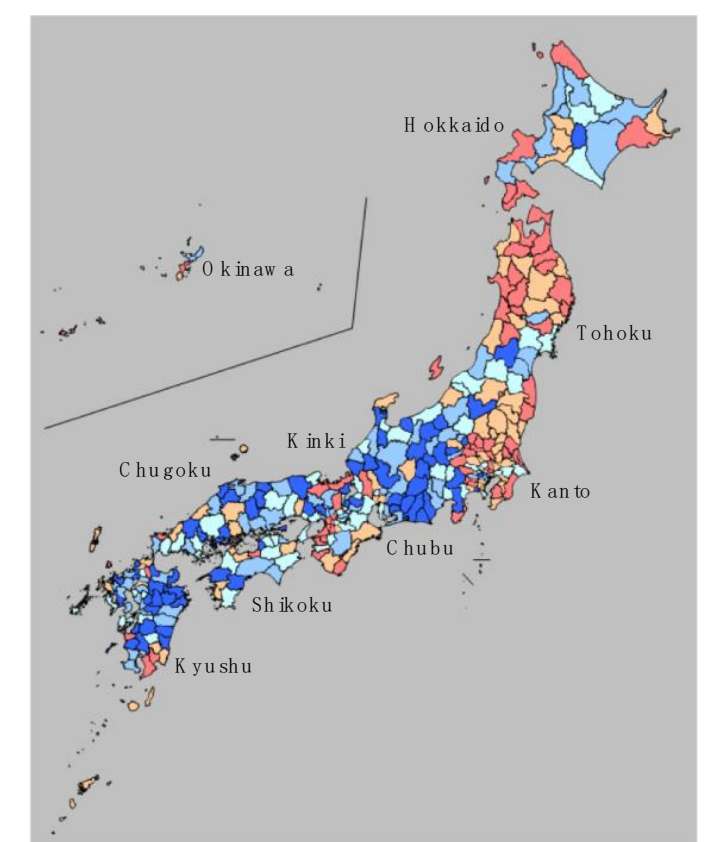

$\leq 83.25$ ( $\leq 20$ th percentile) $\leq 84.28$ ( $\leq 80$ th percentile)

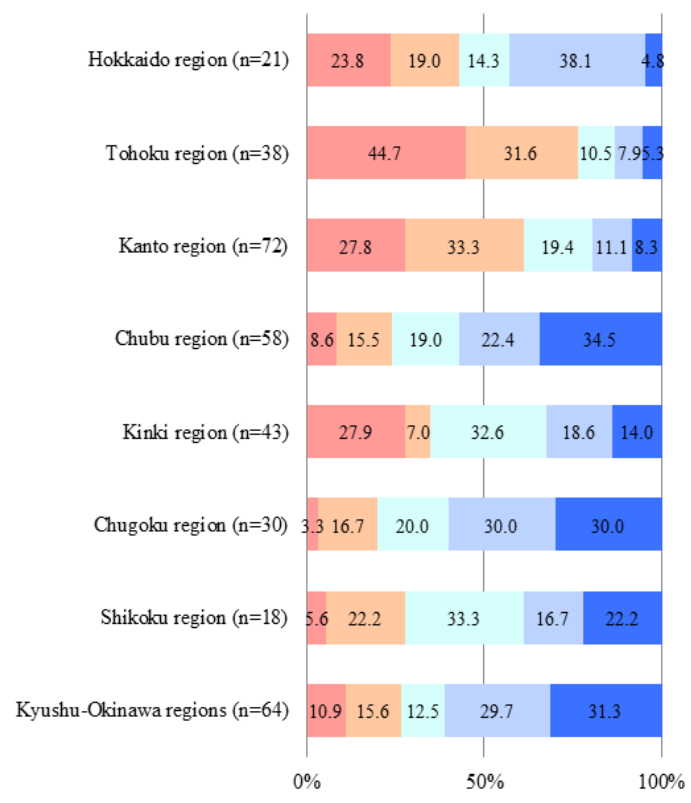

Chi-square test: $p<0.001$ $\leq 83.90$ ( $\leq 60$ th percentile)

Figure 2. Distribution of healthy life expectancy for females in each secondary medical area. Note: Healthy life expectancy was divided into five categories, by 20th percentiles; The " $n$ " means the number of secondary medical areas in eight regions (Hokkaido, Tohoku, Kanto, Chubu, Kinki, Chugoku, Shikoku, and Kyushu-Okinawa regions). 
Table 1. Descriptive statistics for life expectancy and healthy life expectancy (years) at birth.

\begin{tabular}{ccccccccc}
\hline \multirow{2}{*}{ Variables } & \multicolumn{4}{c}{ Males } & \multicolumn{4}{c}{ Females } \\
\cline { 2 - 9 } & $\mathbf{M}$ & SD & Min & Max & M & SD & Min & Max \\
\hline Life expectancy & 80.62 & 0.87 & 78.30 & 82.79 & 86.87 & 0.62 & 85.05 & 88.36 \\
Healthy life expectancy & 79.21 & 0.85 & 76.90 & 81.36 & 83.75 & 0.62 & 81.99 & 85.45 \\
\hline
\end{tabular}

Note: Life expectancy and healthy life expectancy were calculated by the Sullivan method; M: Mean; SD: Standard deviation; Min: Minimum value; Max: Maximum value.

\subsection{Associations Between Healthcare Resources, Life Expectancy, and Healthy Life Expectancy at Birth}

Data for healthcare resource variables (i.e., hospital beds, healthcare workforce, community healthcare service, and healthcare expenditure) are shown in Table 2. Associations between healthcare resources, LE, and HLE at birth are shown in Tables 3 and 4. For both males and females, the numbers of hospital beds were not correlated with LE and HLE, and no significant correlation was observed according to the criteria of this study (i.e., correlations were significant at the $p<0.001$ level, and correlation coefficients greater than 0.2 were considered to indicate a positive correlation). However, for males, the number of curative (acute) care beds per 1000 residents tended to correlate negatively with LE $(r=-0.122, p=0.023)$ and HLE $(r=-0.129, p=0.017)$. In contrast, for females, the number of rehabilitative care beds per 1000 residents tended to correlate positively with LE $(r=0.126, p=0.019)$ and HLE $(r=0.157, p=0.003)$, and long-term care beds per 1000 residents tended to correlate positively with HLE $(r=0.117, p=0.030)$.

Table 2. Descriptive statistics of healthcare resource variables.

\begin{tabular}{|c|c|c|c|c|}
\hline Variables & $\mathbf{M}$ & SD & Min & Max \\
\hline \multicolumn{5}{|c|}{ Hospital beds (number of beds per 1000 residents) } \\
\hline Curative (acute) care & 6.06 & 1.77 & 1.57 & 14.19 \\
\hline Rehabilitative care & 1.41 & 0.83 & 0.00 & 5.05 \\
\hline Long-term care & 3.45 & 2.31 & 0.00 & 17.33 \\
\hline \multicolumn{5}{|c|}{ Healthcare workforce (number of healthcare providers per 1000 residents) } \\
\hline Doctors & 2.45 & 0.87 & 1.12 & 11.89 \\
\hline Nurses & 9.55 & 2.87 & 3.95 & 19.61 \\
\hline Therapists & 1.16 & 0.57 & 0.08 & 4.30 \\
\hline \multicolumn{5}{|c|}{ Home healthcare service (number of facilities per 1000 residents) } \\
\hline Support hospital of home healthcare & 0.01 & 0.01 & 0.00 & 0.10 \\
\hline Support clinic of home healthcare & 0.10 & 0.06 & 0.00 & 0.35 \\
\hline Home-visit care facility & 0.20 & 0.08 & 0.06 & 0.47 \\
\hline \multicolumn{5}{|l|}{ Healthcare expenditure (JPY per capita) } \\
\hline Hospitalization & $153,129.53$ & $31,146.30$ & $91,904.53$ & $253,059.03$ \\
\hline Outpatient & $195,347.25$ & $17,342.34$ & $135,962.50$ & $276,722.07$ \\
\hline Dentistry & $23,966.78$ & 2887.87 & $14,294.20$ & $32,158.29$ \\
\hline
\end{tabular}

Note: The facilities with at least 20 beds are "support hospital of home health care", while the facilities with fewer than 20 beds are "support clinic of home health care". Therapists include physical therapists, occupational therapists, and speech-hearing therapists. JPY: Japanese yen, M: Mean, SD: Standard deviation; Min: Minimum value; Max: Maximum value. 
Table 3. Associations between healthcare resources, life expectancy, and healthy life expectancy at birth for males.

\begin{tabular}{|c|c|c|c|c|c|c|}
\hline \multirow{2}{*}{ Variables } & \multicolumn{3}{|c|}{ Life Expectancy } & \multicolumn{3}{|c|}{ Healthy Life Expectancy } \\
\hline & $r$ & $p$ Value & df & $r$ & $p$ Value & df \\
\hline \multicolumn{7}{|c|}{ Hospital beds (number of beds per 1000 residents) } \\
\hline Curative (acute) care & -0.122 & 0.023 & 341 & -0.129 & 0.017 & 341 \\
\hline Rehabilitative care & 0.022 & 0.686 & 341 & 0.034 & 0.533 & 341 \\
\hline Long-term care & -0.010 & 0.860 & 341 & 0.014 & 0.801 & 341 \\
\hline \multicolumn{7}{|c|}{ Healthcare workforce (number of healthcare providers per 1000 residents) } \\
\hline Doctors & 0.076 & 0.163 & 341 & 0.046 & 0.395 & 341 \\
\hline Nurses & -0.046 & 0.396 & 341 & -0.044 & 0.421 & 341 \\
\hline Therapists & 0.099 & 0.067 & 341 & 0.115 & 0.033 & 341 \\
\hline \multicolumn{7}{|c|}{ Home healthcare service (number of facilities per 1000 residents) } \\
\hline $\begin{array}{l}\text { Support hospital of home } \\
\text { healthcare }\end{array}$ & 0.106 & 0.051 & 341 & 0.106 & 0.049 & 341 \\
\hline $\begin{array}{l}\text { Support clinic of home } \\
\text { healthcare }\end{array}$ & 0.155 & 0.004 & 341 & 0.154 & 0.004 & 341 \\
\hline Home-visit care facility & 0.145 & 0.007 & 341 & 0.134 & 0.013 & 341 \\
\hline \multicolumn{7}{|c|}{ Healthcare expenditure (JPY per capita) } \\
\hline Hospitalization & 0.002 & 0.964 & 341 & 0.004 & 0.940 & 341 \\
\hline Outpatient & 0.180 & $<0.001$ & 341 & 0.176 & 0.001 & 341 \\
\hline Dentistry & 0.228 * & $<0.001$ & 341 & $0.237^{*}$ & $<0.001$ & 341 \\
\hline
\end{tabular}

Note: Partial correlation analyses were performed by controlling for population density; ${ }^{*}$ Correlations were significant at the $p<0.001$ level (two-tailed), and correlation coefficients greater than 0.2 were considered to indicate a positive correlation.

Table 4. Associations between healthcare resources, life expectancy, and healthy life expectancy at birth for females.

\begin{tabular}{|c|c|c|c|c|c|c|}
\hline \multirow{2}{*}{ Variables } & \multicolumn{3}{|c|}{ Life Expectancy } & \multicolumn{3}{|c|}{ Healthy Life Expectancy } \\
\hline & $r$ & $p$ Value & df & $r$ & $p$ Value & df \\
\hline \multicolumn{7}{|c|}{ Hospital beds (number of beds per 1000 residents) } \\
\hline Curative (acute) care & 0.040 & 0.460 & 341 & 0.018 & 0.746 & 341 \\
\hline Rehabilitative care & 0.126 & 0.019 & 341 & 0.157 & 0.003 & 341 \\
\hline Long-term care & 0.068 & 0.208 & 341 & 0.117 & 0.030 & 341 \\
\hline \multicolumn{7}{|c|}{ Healthcare workforce (number of healthcare providers per 1000 residents) } \\
\hline Doctors & $0.220 *$ & $<0.001$ & 341 & 0.154 & 0.004 & 341 \\
\hline Nurses & 0.119 & 0.027 & 341 & 0.134 & 0.013 & 341 \\
\hline Therapists & 0.198 & $<0.001$ & 341 & $0.242 *$ & $<0.001$ & 341 \\
\hline \multicolumn{7}{|c|}{ Home healthcare service (number of facilities per 1000 residents) } \\
\hline Support hospital of home healthcare & 0.182 & $<0.001$ & 341 & 0.190 & $<0.001$ & 341 \\
\hline Support clinic of home healthcare & 0.226 * & $<0.001$ & 341 & $0.222 *$ & $<0.001$ & 341 \\
\hline Home-visit care facility & $0.268 *$ & $<0.001$ & 341 & $0.231 *$ & $<0.001$ & 341 \\
\hline \multicolumn{7}{|l|}{ Healthcare expenditure (JPY per capita) } \\
\hline Hospitalization & 0.192 & $<0.001$ & 341 & 0.180 & $<0.001$ & 341 \\
\hline Outpatient & 0.173 & 0.001 & 341 & 0.141 & 0.009 & 341 \\
\hline Dentistry & 0.132 & 0.015 & 341 & 0.131 & 0.015 & 341 \\
\hline
\end{tabular}

Note: Partial correlation analyses were performed by controlling for population density; * Correlations were significant at the $p<0.001$ level (two-tailed), and correlation coefficients greater than 0.2 were considered to indicate a positive correlation. 
Regarding the healthcare workforce, there was no significant positive correlation with LE and HLE for males; however, therapists per 1000 residents tended to be positively correlated with HLE $(r=0.115$, $p=0.033$ ). For females, doctors per 1000 residents were significantly positively correlated with LE $(r=0.220, p<0.001)$, and therapists per 1000 residents were significantly positively correlated with HLE $(r=0.242, p<0.001)$. Meanwhile, doctors per 1000 residents tended to correlate positively with HLE $(r=0.154, p=0.004)$, nurses per 1000 residents tended to correlate positively with LE $(r=0.119$, $p=0.027)$ and HLE $(r=0.134, p=0.013)$, and therapists per 1000 residents tended to correlate positively with LE $(r=0.198, p<0.001)$.

In terms of home healthcare service, there were no significant correlations with LE and HLE for males. However, support hospitals for home healthcare per 1000 residents tended to correlate positively with HLE $(r=0.106, p=0.049)$. Moreover, support clinics for home healthcare and home-visit care facilities per 1000 residents tended to correlate positively with LE $(r=0.155, p=0.004$ and $r=0.145$, $p=0.007$, respectively) and HLE ( $r=0.154, p=0.004$ and $r=0.134, p=0.013$, respectively). For females, support clinics for home healthcare and home-visit care facilities per 1000 residents were significantly positively correlated with both LE $(r=0.226, p<0.001$ and $r=0.268, p<0.001$, respectively) and HLE $(r=0.222, p<0.001$ and $r=0.231, p<0.001$, respectively). Support hospitals for home healthcare per 1000 residents tended to correlate positively with LE $(r=0.182, p<0.001)$ and HLE $(r=0.190, p<0.001)$.

For healthcare expenditure, for males, dentistry expenditure per capita was significantly positively correlated with both LE $(r=0.228, p<0.001)$ and HLE $(r=0.237, p<0.001)$, while outpatient expenditure per capita tended to correlate positively with LE $(r=0.180, p<0.001)$ and HLE $(r=0.176, \mathrm{p}=0.001)$. For females, healthcare expenditure did not have a significant correlation with LE and HLE. However, hospitalization, outpatient, and dentistry expenditure per capita tended to correlate positively with LE $(r=0.192, p<0.001, r=0.173, p=0.001$, and $r=0.132, p=0.015$, respectively) and HLE ( $r=0.180$, $p<0.001, r=0.141, p=0.009$, and $r=0.131, p=0.015$, respectively).

\section{Discussion}

This study aimed to reveal the descriptive features of the distribution of HLE across secondary medical areas in Japan. In addition, the relationship among healthcare resources, LE, and HLE was examined through a geographical study of all secondary medical areas in Japan. The findings revealed significant regional disparities regarding HLE despite controlling for population density. This indicates the need for action and execution of programs aimed at reducing regional disparities. For males, the proportion of secondary medical areas with short HLE was higher in the northern part of Japan (Hokkaido and Tohoku regions), while areas with higher rates of high HLE were in the central (Chubu region) and west-central (Kinki regions) parts. For females, the proportion of secondary medical areas with short HLE was higher in the northern (Tohoku region) and northern-central (Kanto region) parts of Japan, while areas with higher rates of high HLE were in the central (Chubu region) and southern (Kyushu-Okinawa regions) parts. The above results indicate that for both males and females, the proportion of areas with short HLE was higher in the northern part of Japan (Tohoku region), and the areas with higher rates of high HLE were in the central part (Chubu region). Thus, this suggests that there are inequalities in HLE across secondary medical areas in Japan.

Previous research suggests that healthcare resources, including the number of beds, can affect health. However, in this study, hospital beds were not significantly correlated with LE and HLE for either males or females at birth. This lack of correlation might be explained by the fact that hospital beds are well-deployed in Japan [52,53]. Although there was no significant association between the number of beds and LE and HLE, a negative trend for acute care beds and health outcomes was observed; that is, for males, curative (acute) care beds per 1000 residents were negatively correlated with LE and HLE. This finding is consistent with previous studies that found that providing an excessive number of beds was negatively associated with health outcomes [34]. Overall, the level of health resources, including human and physical resources, is positively correlated with better health outcomes (i.e., decreased death rates and prolonged life). Ultimately, policymakers should consider 
the optimal levels of health resources in terms of number of physicians, nurses, and beds to achieve better health outcomes. In addition, they should consider the potential negative effects of oversupply on population health.

Regarding the healthcare workforce, for females, doctors per 1000 residents were significantly positively correlated with LE and tended to correlate positively with HLE; conversely, therapists per 1000 residents were significantly positively correlated with HLE and tended to correlate positively with LE. For males, therapists per 1000 residents tended to correlate positively with HLE. Prior studies suggested that healthcare resources have short- and long-term effects on health. In addition, multiple studies revealed that countries with higher levels of human health resources (e.g., number of physicians) typically have better overall population health (e.g., LE and mortality rate) [54]. Studies on international differences on the impact of the number of doctors on health reported that doctors per capita were an important determinant of mortality [55-57]. Mortality rate has a negative correlation with the number of doctors, which seems reasonable since a sufficient number of doctors who can diagnose diseases and provide appropriate care services can mitigate certain causes of death. Therefore, the number of doctors may be related to LE and HLE.

Furthermore, in this study, the number of therapists was also significantly associated with HLE; Rehabilitative health services are expected to extend HLE, since rehabilitation is aimed at optimizing individual functions related to health status [58]. Rehabilitation practitioners include physical therapists, occupational therapists, and speech-hearing therapists. As aging of the population has a serious impact on social systems, it is important to address people's functioning, including restricted functions that affect their daily activities. Considering the effect of healthcare worker availability on health, the need to improve cross-region heterogeneity is significant. Thus, the healthcare workforce can be a facilitating factor of LE and HLE. However, the link between rehabilitation of human resources and health outcomes has not been fully validated and further evaluations are required in the future.

Home health resources were related to LE and HLE. For females, support clinics for home healthcare and home-visit care facilities per 1000 residents had significant positive correlations with both LE and HLE. On the other hand, for males, support clinics for home healthcare and home-visit care facilities per 1000 residents tended to be positively correlated with LE and HLE. Visiting medical care can be improved by increasing the efficiency and collaboration between care service dealers, clinics, and hospitals. Improving home-based medical care and nursing, which include end-of-life care that is in keeping with the individual's values, can enhance both LE and HLE. Studies have noted that access to a primary care service has a strong and significant influence on longer LE and lower mortality rates $[59,60]$. Primary care typically involves a wide range of contents, including prevention and treatment. Prior studies at the regional level demonstrated that higher availability of primary care services was associated with fewer incidences of disabilities and mortality $[59,60]$. Although the Japanese healthcare system is open and flexible regarding healthcare provision and access [11], it cannot be said that home-based medical care is adequate, as has been noted in this study. Moreover, ranges of distribution in home healthcare service among secondary medical areas were observed in this study (see Table 2). Home healthcare services can be a facilitating factor of LE and HLE. However, while the effect of hospital healthcare resources on health outcomes has been reported, the link between home healthcare services and health outcomes has not been fully clarified, thus warranting further investigation in the future.

Regarding healthcare expenditure, for males, dentistry expenditure per capita was significantly positively correlated with both LE and HLE; for females, dentistry expenditure per capita tended to correlate positively with both LE and HLE. Dental expenditure seems to be associated with the level of access to oral care. To prevent loss of teeth, it is important to maintain oral health $[61,62]$. Although the basic step to maintaining oral health is oral self-care, making an accurate self-assessment of oral health status is difficult. Thus, it is important for older adults to visit dental health experts for regular prevention and treatment. Oral health is one of the key markers of overall health, well-being, and QOL [63]. In addition, oral diseases are risk factors for various diseases [64-66]. For instance, 
oral diseases are related to physical illnesses, such as infections and cardiovascular diseases. In addition, missing teeth is a risk factor for decline of cognitive competence [67]. Oral diseases are chronic and cumulative in nature and aggravate over time [68]. In addition, dental care costs may be affected by socioeconomic factors; socioeconomic differences are associated with LE and healthy and disease-free LE [69]. These findings concur with the present findings, which highlights the importance of providing appropriate prevention and treatment services to maintain dental health and functioning in later life.

In this study, regarding the association between healthcare resources and health outcomes, males had lower or non-significant correlation values compared to females. Lower point estimates among males compared to females can be explained by the fact that the difference between LE and HLE (i.e., unhealthy life expectancy) is higher among females than among males; in this study, the differences were 1.41 years and 3.12 years for males and females, respectively. In addition, similar to Japan, unhealthy life expectancy tends to be higher in females than in males in other countries [10]. In general, males and females differ in terms of various health outcomes, including mortality and morbidity $[70,71]$. In the present study, a shorter LE and HLE among males compared to females, as well as other limitations, may have affected the relationship between LE, HLE, and healthcare resources. Factors related to lifestyle that affect morbidity and mortality, including health-related behavior, might explain the gender gap in health expectancy [72-78]. However, the predictors of gender differences in environmental factors and HLE have not been fully clarified. In order to continue developing effective approaches, it is necessary to identify the factors affecting gender differences.

In this study, the distribution of HLE conducted at the secondary care area level is consistent with a previous study conducted at the prefecture level in Japan [21]. The study conducted at the prefecture level suggested that behavioral risk factors made a greater contribution to both disability-adjusted life years and mortality, and that the most important behavioral risk factors for health outcomes were unhealthy diet and smoking. Substantial opportunities for a healthier population exist via modifiable risk factor approaches. However, since it is difficult to identify a specific factor that affects HLE, there are possibilities of interplay among various factors, including healthcare system and lifestyle [14,15]. In this study, there were no strong associations between healthcare resources and HLE; however, factors other than healthcare resources could have a possible impact on HLE. People living in regions with higher HLE might have better lifestyles, including more efficient prevention and treatment of diseases. Thus, to continue developing effective approaches, it is necessary to identify the factors from multifaceted viewpoints. It is important to consider not only the optimal levels of health resources, but also lifestyle factors, in order to improve HLE.

\section{Limitations}

This study had several limitations. First, there is a possible bias of geographical fallacy, as this study model was a geographical study. Second, although we analyzed the relationship between medical resources, LE, and HLE, adjusting for population density alone, other factors were not adjusted; thus, it is difficult to determine a specific factor. Various other confounding factors may need to be controlled for in future studies. Third, although the findings of this study concur with some of those of previous studies conducted in other countries, it should be noted that this study was conducted only in Japan. As all data were collected in Japan, it is difficult to generalize the results to other countries.

\section{Conclusions}

In the present study, inequalities in HLE were found despite controlling for population density. This indicates the need to promote social policies designed to reduce regional disparities. As described above, some factors related to healthcare resources were significantly related to LE and HLE; the numbers of doctors and therapists, support clinics for home healthcare facilities and home-visit treatments, and dentistry expenditure per capita were positively correlated with LE and HLE. Most of our findings were consistent with previous studies conducted in other countries that have different levels of healthcare systems; multiple studies have shown that the most important factor that contributes 
to a population's health status is healthcare resources, which include the number of beds and healthcare professionals. On the other hand, this study may indicate an important factor in countries with high-quality healthcare systems, since there is limited research on the relationship between healthcare resources, such as healthcare workforce, home healthcare facilities, and home-visit treatments, and HLE. Ultimately, policymakers should consider the optimal levels of healthcare resources in order to improve LE and HLE. Our results suggest the necessity to consider the geographical redistribution of healthcare resources. In addition, further studies are needed to ensure a more effective and balanced geographical distribution of healthcare systems in Japan.

Supplementary Materials: The following are available online at http://www.mdpi.com/1660-4601/17/17/6301/s1, Table S1: Types of long-term care (Japanese care system).

Author Contributions: Conceptualization, T.O. and N.K.; Methodology, R.H. and T.O.; Software, R.H. and T.O.; Validation, R.H. and T.O.; Formal analysis, R.H. and T.O.; Investigation, R.H. and T.O.; Resources, R.H. and T.O.; Data Curation, R.H. and T.O.; Writing-original draft preparation, R.H.; Writing-review and editing, T.O., T.M., J.A., K.K., N.K.; Visualization, R.H. and T.O.; Supervision, T.O.; Project Administration, T.O. and N.K.; Funding Acquisition, N.K. All authors have read and agreed to the published version of the manuscript.

Funding: This work was funded by Health Labour Sciences Research Grant (grant number 19FA1012) and Health Labour Sciences Research Grant (grant number 19FA2001).

Acknowledgments: The authors gratefully acknowledge all persons who contributed to this study.

Conflicts of Interest: The authors declare no conflict of interest.

\section{References}

1. Kassebaum, N.J.; Arora, M.; Barber, R.M.; Bhutta, Z.A.; Brown, J.; Carter, A.; Casey, D.C.; Charlson, F.J.; Coates, M.M.; Coggeshall, M.; et al. Global, regional, and national disability-adjusted life years (DALYs) for 315 diseases and injuries and healthy life expectancy (HALE), 1990-2015: A systematic analysis for the global burden of disease study 2015. Lancet 2015, 388, 1603-1658. [CrossRef]

2. Murray, C.J.; Barber, R.M.; Foreman, K.J.; Abbasoglu Ozgoren, A.; Abd-Allah, F.; Abera, S.F.; Aboyans, V.; Abraham, J.P.; Abubakar, I.; Abu-Raddad, L.J.; et al. Global, regional, and national disability-adjusted life years (DALYs) for 306 diseases and injuries and healthy life expectancy (HALE) for 188 countries, 1990-2013: Quantifying the epidemiological transition. Lancet 2015, 386, 2145-2191. [CrossRef]

3. World Health Organization. An Overarching Health Indicator for the Post-2015 Development Agenda. Brief Summary of Some Proposed Candidate Indicators. Available online: https://www.who.int/healthinfo/ indicators/hsi_indicators_SDG_TechnicalMeeting_December2015_BackgroundPaper.pdf\#search=\%27An+ overarching+health+indicator+for+the+post2015+development+agenda.+Brief+summary+of+some+ proposed+candidate+indicators.+Background+paper+for+expert+consultation $\% 27$ (accessed on 24 July 2020).

4. Murray, C.J.; Salomon, J.A.; Mathers, C. A critical examination of summary measures of population health. Bull. World Health Organ. 2000, 78, 981-994. [PubMed]

5. Saito, Y.; Robine, J.M.; Crimmins, E.M. The methods and materials of health expectancy. Stat. J. IAOS 2014, 30, 209-223. [CrossRef] [PubMed]

6. Vos, T.; Allen, C.; Arora, M.; Barber, R.M.; Bhutta, Z.A.; Brown, A.; Carter, A.; Casey, D.C.; Charlson, F.J.; Chen, A.Z.; et al. Global, regional, and national incidence, prevalence, and years lived with disability for 310 diseases and injuries, 1990-2015: A systematic analysis for the Global Burden of Disease Study. Lancet 2015, 388, 1545-1602. [CrossRef]

7. Brown, G.C. Living too long: The current focus of medical research on increasing the quantity, rather than the quality, of life is damaging our health and harming the economy. EMBO Rep. 2015, 16, 137-141. [CrossRef]

8. Brayne, C. The elephant in the room-Healthy brains in later life, epidemiology and public health. Nat. Rev. Neurosci. 2007, 8, 233-239. [CrossRef]

9. Salomon, J.A.; Wang, H.; Freeman, M.K.; Vos, T.; Flaxman, A.D.; Lopez, A.D.; Murray, C.J. Healthy life expectancy for 187 countries, 1990-2010: A systematic analysis for the global burden disease study 2010. Lancet 2012, 380, 2144-2162. [CrossRef] 
10. World Health Organization. WHO the Global Health Observatory. Available online: https://www.who.int/data/gho/data/themes/topics/indicator-groups/indicator-group-details/GHO/ life-expectancy-and-healthy-life-expectancy (accessed on 24 July 2020).

11. Organisation for Economic Co-Operation and Development. OECD Reviews of Health Care Quality, Japan 2015. Available online: https://www.oecd.org/publications/oecd-reviews-of-health-care-quality-japan-20159789264225817-en.htm (accessed on 24 July 2020).

12. Ikegami, N.; Yoo, B.K.; Hashimoto, H.; Matsumoto, M.; Ogata, H.; Babazono, A.; Watanabe, R.; Shibuya, K.; Yang, B.M.; Reich, M.R.; et al. Japanese universal health coverage: Evolution, achievements, and challenges. Lancet 2011, 378, 1106-1115. [CrossRef]

13. Jones, R.S. Health-care reform in Japan: Controlling costs, improving quality and ensuring equity. In $O E C D$ Economics Department Working Papers; OECD: Paris, France, 2009.

14. Shimazu, T.; Kuriyama, S.; Hozawa, A.; Ohmori, K.; Sato, Y.; Nakaya, N.; Nishino, Y.; Tsubono, Y.; Tsuji, I. Dietary patterns and cardiovascular disease mortality in Japan: A prospective cohort study. Int. J. Epidemiol. 2007, 36, 600-609. [CrossRef]

15. Sakata, T. A Very-Low-Calorie conventional Japanese diet: Its implications for prevention of obesity. Obes. Res. 1995, 3, 233s-239s. [CrossRef] [PubMed]

16. Public Health England. Chapter 1. Life expectancy and healthy life expectancy. In Health Profile for England; Public Health England: London, UK, 2017.

17. Hashimoto, S.; Kawado, M.; Seko, R.; Murakami, Y.; Hayashi, M.; Kato, M.; Noda, T.; Ojima, T.; Nagai, M.; Tsuji, I. Trends in disability-free life expectancy in Japan, 1995-2004. J. Epidemiol. 2010, 20, 308-312. [CrossRef] [PubMed]

18. National Institute of Health and Nutrition. Health Japan 21 (the Second Term). Available online: http: //www.nibiohn.go.jp/eiken/kenkounippon21/en/ (accessed on 24 July 2020).

19. Ministry of Health, Labour and Welfare of Japan. Health Japan 21 (the Second Term). Available online: https://www.mhlw.go.jp/stf/seisakunitsuite/bunya/kenkou_iryou/kenkou/kenkounippon21.html (accessed on 24 July 2020). (In Japanese)

20. Hashimoto, S. Health and Labour Sciences Research Grants "Study on Evaluation of Transition in Healthy Life Expectancy". Available online: http://toukei.umin.jp/kenkoujyumyou/houkoku/H29.pdf (accessed on 24 July 2020). (In Japanese).

21. Nomura, S.; Sakamoto, H.; Glenn, S.; Tsugawa, Y.; Abe, S.K.; Md Rahman, M.; Brown, J.C.; Ezoe, S.; Fitzmaurice, C.; Inokuchi, T.; et al. Population health and regional variations of disease burden in Japan 1990-2015: A systematic subnational analysis for the Global Burden of Disease Study 2015. Lancet 2017, 390, 1521-1538. [CrossRef]

22. World Health Organization. Japan Health System Review. Available online: https://apps.who.int/iris/bitstream/handle/10665/259941/9789290226260-eng.pdf;jsessionid= 41C4E159BB22C5BC0CA610FAF4EF7240?sequence=1 (accessed on 24 July 2020).

23. Tanihara, S.; Zhang, T.; Ojima, T.; Nakamura, Y.; Yanagawa, H.; Kobayashi, M. Geographic distribution of medical supplies and the numbers of hospital inpatients in the secondary medical areas in Japan. Nihon. Koshu. Eisei. Zasshi. 1997, 44, 688-693. (In Japanese)

24. Organisation for Economic Co-Operation and Development. OECD Factbook 2015-2016: Economic, Environmental and Social Statistics. Available online: https://www.oecd.org/publications/oecd-factbook18147364.htm (accessed on 24 July 2020).

25. Statistics Bureau of Japan. Annual Report 1999. Available online: https://www.e-stat.go.jp/en/stat-search/ files?page $=1 \&$ layout $=$ datalist $\&$ toukei $=00200524 \&$ tstat $=000000090001 \&$ cycle $=7 \&$ year $=19990 \&$ month $=0 \&$ tclass1=000001011679 (accessed on 24 July 2020).

26. Statistics Bureau of Japan. Annual Report 2019. Available online: http://www.stat.go.jp/english/data/jinsui/ 2019np/index.html (accessed on 24 July 2020).

27. Statistics Bureau of Japan. Japan Statistical Yearbook 2019. Available online: http://www.stat.go.jp/english/ data/nenkan/68nenkan/index.html (accessed on 24 July 2020).

28. Tamiya, N.; Noguchi, H.; Nishi, A.; Reich, M.R.; Ikegami, N.; Hashimoto, H.; Shibuya, K.; Kawachi, I.; Campbell, J.C. Population ageing and wellbeing: Lessons from Japan's long-term care insurance policy. Lancet 2011, 378, 1183-1192. [CrossRef] 
29. Tsugawa, Y.; Hasegawa, K.; Hiraide, A.; Jha, A.K. Regional health expenditure and health outcomes after out-of-hospital cardiac arrest in Japan: An observational study. BMJ Open 2015, 5, e008374. [CrossRef]

30. Fukuda, Y.; Nakamura, K.; Takano, T. Cause-specific mortality differences across socioeconomic position of municipalities in Japan, 1973-1977 and 1993-1998: Increased importance of injury and suicide in inequality for ages under 75. Int. J. Epidemiol. 2005, 34, 100-109. [CrossRef]

31. Nakamura, T. The development of medical networks through ICT in Japan. Netcom 2007, 21, 363-380. [CrossRef]

32. Hashimoto, H.; Ikegami, N.; Shibuya, K.; Izumida, N.; Noguchi, H.; Yasunaga, H.; Miyata, H.; Acuin, J.M.; Reich, M.R. Cost containment and quality of care in Japan: Is there a trade-off? Lancet 2011, 378, 1174-1182. [CrossRef]

33. Hamada, H.; Lapalme-Remis, S. International perspective on mixed health care: Japan. McGill J. Med. 2008, 11, 79-80.

34. Hosseini Jebeli, S.S.; Hadian, M.; Souresrafil, A. Study of health resource and health outcomes: Organization of economic corporation and development panel data analysis. J. Educ. Health Promot. 2019, 8, 70. [CrossRef] [PubMed]

35. Chan, M.F. The impact of health care resources, socioeconomic status, and demographics on life expectancy: A cross-country study in three southeast Asian countries. Asia Pac. J. Public Health 2015, 27, NP972-NP983. [CrossRef] [PubMed]

36. Qin, X.; Hsieh, C.R. Economic growth and the geographic maldistribution of health care resources: Evidence from China, 1949-2010. China Econ. Rev. 2014, 31, 228-246. [CrossRef]

37. Zhang, X.; Oyama, T. Investigating the health care delivery system in Japan and reviewing the local public hospital reform. Risk Manag. Healthc. Policy 2016, 9, 21-32. [CrossRef] [PubMed]

38. Sullivan, D.F. A single index of mortality and morbidity. HSMHA Health Rep. 1971, 86, 347-354. [CrossRef] [PubMed]

39. Statistics Bureau of Japan. Resident Registry Data 2017. Available online: https://www.e-stat.go.jp/statsearch/files? page $=1 \&$ layout $=$ datalist $\&$ toukei $=00200241 \&$ kikan $=00200 \&$ tstat $=000001039591 \&$ cycle $=7 \&$ year=20170\&month=0\&tclass1=000001039601\&result_back=1 (accessed on 24 July 2020).

40. Statistics Bureau of Japan. Vital Statistics 2017, 2018, 2019. Available online: https: //www.e-stat.go.jp/stat-search/files?page=1\&layout=datalist\&toukei=00450011\&bunya_1=02\&tstat= $000001028897 \&$ cycle $=7 \&$ tclass $1=000001053058 \&$ tclass $2=000001053061 \&$ tclass $3=000001053074 \&$ tclass $4=$ 000001053085\&result_page $=1$ (accessed on 24 July 2020).

41. Tsutsui, T.; Muramatsu, N. Japan's universal long-term care system reform of 2005: Containing costs and realizing a version. J. Am. Geriatr. Soc. 2007, 55, 1458-1463. [CrossRef] [PubMed]

42. Shinjuku City Long-term Care Insurance Division. Guidebook for Long-term Care Insurance. Available online: http://www.foreign.city.shinjuku.lg.jp/en/wp-content/uploads/sites/4/2018/10/kaigo2018_e.pdf\# search $=\% 27$ longterm + care + japan + level $+1+2+3+4+5 \% 27$ (accessed on 24 July 2020).

43. Statistics Bureau of Japan. Report on Long-Term Care Insurance Services 2017. Available online: https://www. e-stat.go.jp/stat-search/files?page=1\&toukei=00450351\&tstat=000001031648 (accessed on 24 July 2020).

44. Statistics Bureau of Japan. Survey of Medical Institutions 2017. Available online: https://www.e-stat.go.jp/ stat-search/files?page $=1 \&$ toukei=00450021\&tstat $=000001030908$ (accessed on 24 July 2020).

45. Ministry of Health, Labour and Welfare. Annual Report on Health, Labour and Welfare 2018 (Data in 2017). Available online: https://www.mhlw.go.jp/wp/hakusyo/kousei/18/dl/all.pdf (accessed on 24 July 2020).

46. Ministry of Health, Labour and Welfare. Iryohi no Chiikisa Bunseki 2017. Available online: https://www. mhlw.go.jp/stf/seisakunitsuite/bunya/kenkou_iryou/iryouhoken/database/iryomap/index.html (accessed on 24 July 2020).

47. Ministry of Health, Labour and Welfare. Study Group for Reviewing Medical Plans. Working Group for Home Medical Care System. Available online: https://www.mhlw.go.jp/file/05-Shingikai-12404000Hokenkyoku-Iryouka/0000161550.pdf (accessed on 24 July 2020).

48. Kato, D.; Ryu, H.; Matsumoto, T.; Abe, K.; Kaneko, M.; Ko, M.; Irving, G.; Ramsay, R.; Kondo, M. Building primary care in Japan: Literature review. J. Gen. Fam. Med. 2019, 20, 170-179. [CrossRef]

49. Holzer, C.E.; Goldsmith, H.F.; Ciarlo, J.A. The availability of health and mental health providers by population density. J. Wash. Acad. Sci. 2000, 86, 25-33. 
50. Statistics Bureau of Japan. Population Census 2015. Available online: https://www.e-stat.go.jp/en/stat-search/ files?page=1\&toukei=00200521 (accessed on 24 July 2020).

51. WELLNESS. Co, Ltd. Database System of Secondary Medical Areas (In Japanese). Available online: https://www.wellness.co.jp/siteoperation/msd/ (accessed on 24 July 2020).

52. Reich, M.R.; Shibuya, K. The future of Japan's health system-Sustaining good health with equity at low cost. N. Engl. J. Med. 2015, 373, 1793-1797. [CrossRef]

53. Ikegami, N.; Campbell, J.C. Japan's health care system: Containing costs and attempting reform. Health Aff. 2004, 23, 26-36. [CrossRef]

54. Farahani, M.; Subramanian, S.V.; Canning, D. The effect of changes in health sector resources on infant mortality in the short-run and the long-run: A longitudinal econometric analysis. Soc. Sci. Med. 2009, 68, 1918-1925. [CrossRef] [PubMed]

55. McGovern, M.E.; Canning, D. Vaccination and all-cause child mortality from 1985 to 2011: Global evidence from the demographic and health surveys. Am. J. Epidemiol. 2015, 182, 791-798. [CrossRef] [PubMed]

56. Shetty, A.; Shetty, S. The impact of doctors per capita on the mortality rate in Asia. Int. J. Med. Pharm. Sci. 2014, 4, 10-15.

57. Or, Z.; Wang, J.; Jamison, D. International differences in the impact of doctors on health: A multilevel analysis of OECD Countries. J. Health Econ. 2005, 24, 531-560. [CrossRef] [PubMed]

58. Stucki, G.; Cieza, A.; Melvin, J. The international classification of functioning, disability and health (ICF): A unifying model for the conceptual description of the rehabilitation strategy. J. Rehabil. Med. 2007, 39, 279-285. [CrossRef]

59. Basu, S.; Berkowitz, S.A.; Phillips, R.L.; Bitton, A.; Landon, B.E.; Phillips, R.S. Association of primary care physician supply with population mortality in the United States, 2005-2015. JAMA Intern. Med. 2019, 179, 506-514. [CrossRef]

60. Starfield, B.; Shi, L.; Macinko, J. Contribution of primary care to health systems and health. Milbank Q. 2005, 83, 457-502. [CrossRef]

61. Aida, J.; Morita, M.; Akhter, R.; Aoyama, H.; Masui, M.; Ando, Y. Relationships between patient characteristics and reasons for tooth extraction in Japan. Commun. Dent. Health 2009, 26, 104-109.

62. Aida, J.; Ando, Y.; Akhter, R.; Aoyama, H.; Masui, M.; Morita, M. Reasons for permanent tooth extractions in Japan. J. Epidemiol. 2006, 16, 214-219. [CrossRef]

63. Haag, D.G.; Peres, K.G.; Balasubramanian, M.; Brennan, D.S. Oral conditions and health-related quality of life: A systematic review. J. Dent. Res. 2017, 96, 864-874. [CrossRef]

64. Wu, B.; Fillenbaum, G.G.; Plassman, B.L.; Guo, L. Association between oral health and cognitive status: A systematic review. J. Am. Geriatr. Soc. 2016, 4, 739-751. [CrossRef] [PubMed]

65. Polzer, I.; Schwahn, C.; Völzke, H.; Mundt, T.; Biffar, R. The association of tooth loss with all-cause and circulatory mortality. Is there a benefit of replaced teeth? A systematic review and meta-analysis. Clin. Oral Investig. 2012, 16, 333-351. [CrossRef]

66. Kebschull, M.; Demmer, R.T.; Papapanou, P.N. “Gum bug, leave my heart alone!"-Epidemiologic and mechanistic evidence linking periodontal infections and atherosclerosis. J. Dent. Res. 2010, 89, 879-902. [CrossRef]

67. Sanders, C.; Behrens, S.; Schwartz, S.; Wengreen, H.; Corcoran, C.D.; Lyketsos, C.G.; Tschanz, J.T. Nutritional status is associated with faster cognitive decline and worse functional impairment in the progression of dementia: The cache county dementia progression study. J. Alzheimers Dis. 2016, 52, 33-42. [CrossRef] [PubMed]

68. Kassebaum, N.J.; Smith, A.G.C.; Bernabé, E.; Fleming, T.D.; Reynolds, A.E.; Vos, T.; Murray, C.J.L.; Marcenes, W. Global, regional, and national prevalence, incidence, and disability-adjusted life years for oral conditions for 195 countries, 1990-2015: A systematic analysis for the global burden of diseases, injuries, and risk factors. J. Dent. Res. 2017, 96, 380-387. [CrossRef] [PubMed]

69. Head, J.; Chungkham, H.S.; Hyde, M.; Zaninotto, P.; Alexanderson, K.; Stenholm, S.; Salo, P.; Kivimäki, M.; Goldberg, M.; Zins, M.; et al. Socioeconomic differences in healthy and disease-free life expectancy between ages 50 and 75: A multi-cohort study. Eur. J. Public Health 2019, 29, 267-272. [CrossRef]

70. Oksuzyan, A.; Brønnum-Hansen, H.; Jeune, B. Gender gap in health expectancy. Eur. J. Ageing 2010, 7, 213-218. [CrossRef] 
71. Barford, A.; Dorling, D.; Davey Smith, G.; Shaw, M. Life expectancy: Women now on top everywhere. BMJ 2006, 332, 808. [CrossRef]

72. Moreno, X.; Albala, C.; Lera, L.; Leyton, B.; Angel, B.; Sánchez, H. Gender, nutritional status and disability-free life expectancy among older people in Santiago, Chile. PLoS ONE 2018, 13, e0194074. [CrossRef]

73. Sundberg, L.; Agahi, N.; Fritzell, J.; Fors, S. Why is the gender gap in life expectancy decreasing? The impact of age- and cause-specific mortality in Sweden 1997-2014. Int. J. Public Health 2018, 63, 673-681. [CrossRef]

74. Stenholm, S.; Head, J.; Kivimäki, M.; Kawachi, I.; Aalto, V.; Zins, M.; Goldberg, M.; Zaninotto, P.; Magnuson Hanson, L.; Westerlund, H.; et al. Smoking, physical inactivity and obesity as predictors of healthy and disease-free life expectancy between Ages 50 and 75: A multicohort study. Int. J. Epidemiol. 2016, 45, 1260-1270. [CrossRef] [PubMed]

75. Le, Y.; Ren, J.; Shen, J.; Li, T.; Zhang, C.F. The changing gender differences in life expectancy in Chinese cities 2005-2010. PLoS ONE 2015, 10, e123320. [CrossRef] [PubMed]

76. Rochelle, T.L.; Yeung, D.K.Y.; Bond, M.H.; Li, L.M.W. Predictors of the gender gap in life expectancy across 54 nations. Psychol. Health Med. 2015, 20, 129-138. [CrossRef]

77. Van Oyen, H.; Nusselder, W.; Jagger, C.; Kolip, P.; Cambois, E.; Robine, J.M. Gender differences in healthy life years within the EU: An exploration of the "health-survival" paradox. Int. J. Public Health 2013, 58, 143-155. [CrossRef]

78. Van Oyen, H.; Cox, B.; Jagger, C.; Cambois, E.; Nusselder, W.; Gilles, C.; Robine, J.M. Gender gaps in life expectancy and expected years with activity limitations at age 50 in the European Union: Associations with macro-level structural indicators. Eur. J. Ageing 2010, 7, 229-237. [CrossRef] [PubMed]

(C) 2020 by the authors. Licensee MDPI, Basel, Switzerland. This article is an open access article distributed under the terms and conditions of the Creative Commons Attribution (CC BY) license (http://creativecommons.org/licenses/by/4.0/). 